\title{
Home oxygen therapy
}

\section{SUMMARY}

Long-term home oxygen therapy improves survival in patients with chronic obstructive pulmonary disease and persistent, severe hypoxaemia. It is uncertain that this benefit extends to patients with other chronic lung diseases.

Oxygen is a treatment for hypoxaemia, not breathlessness. To confirm hypoxaemia, blood gas analysis is recommended before prescribing oxygen.

There is limited and conflicting evidence that portable oxygen for exertional use is of benefit to patients with chronic obstructive pulmonary disease who do not have severe hypoxaemia. Laboratory studies show improvements in exercise capacity and dyspnoea, but these do not translate into significant benefits in the home setting.

Patients should be educated regarding the expected benefits, risks and burdens of home oxygen therapy. It is particularly important that the patient does not smoke.

\section{Introduction}

Oxygen is a drug that is often used in medical emergencies. ' The gas may also be prescribed for longer term use by patients with chronic respiratory conditions. Oxygen is indicated for the treatment of hypoxaemia, but not for the symptom of breathlessness.

Long-term oxygen therapy is most frequently prescribed for patients with chronic obstructive pulmonary disease (COPD). While oxygen can improve survival, not all patients will benefit, therefore the prescription of oxygen therapy should be guided by the evidence from clinical trials. While the results of studies in COPD have been extrapolated to hypoxaemic patients with other lung diseases, the evidence for benefit is lacking.

\section{Long-term continuous oxygen therapy}

The prescription of long-term continuous oxygen therapy is based on two studies that showed improved survival in patients with COPD and severe hypoxaemia. ${ }^{2,3}$ In the UK Medical Research Council study, patients were prescribed 15 hours of oxygen per day or no oxygen. Mortality at three years was $66 \%$ in the control group and $42.5 \%$ in the oxygen group. ${ }^{2}$ Patients in the US Nocturnal Oxygen Treatment Trial (NOTT) were prescribed continuous oxygen (averaging about 18 hours/day) or nocturnal oxygen. Mortality in the nocturnal oxygen therapy group was 1.94 times that of the continuous oxygen therapy group $(p=0.01){ }^{3}$
The results of these trials significantly altered the treatment of hypoxaemic COPD. Domiciliary oxygen was until recently the only therapy (apart from smoking cessation) known to significantly reduce mortality. Most international guidelines are based on the entry criteria for these trials. They recommend that oxygen should be considered for patients with stable COPD, who have an oxygen partial pressure in arterial blood $\left(\mathrm{PaO}_{2}\right)$ of:

- $55 \mathrm{mmHg}$ or less at rest when awake and breathing air

- $\quad 56-59 \mathrm{mmHg}$ if they have polycythaemia (haematocrit $>0.55$ ) or clinical, electrocardiographic or echocardiographic evidence of pulmonary hypertension or right heart failure.

Before prescribing oxygen, the patient's condition must be stable and all reversible factors, such as the underlying lung disease and comorbidities, for example anaemia or sleep apnoea, should have been treated as much as possible. Continuous oxygen is delivered via a stationary concentrator - an electrically powered device that extracts nitrogen from room air - and should be prescribed for at least 15 hours per day. The flow rate should be set to maintain $\mathrm{PaO}_{2}$ above $60 \mathrm{mmHg}$, at rest. Consideration may be given to increasing flow rates by $1 \mathrm{~L} /$ minute during sleep, exertion and air travel.

Oxygen from a portable cylinder or battery-powered portable oxygen concentrator may be provided for use outside the house for patients who are physically active and wish to maximise the number of hours they receive oxygen.

\section{Christine F McDonald} Director, Department of Respiratory and Sleep Medicine

Medical director, Institute for Breathing and Sleep'

Professorial fellow ${ }^{2}$

'Austin Health, Melbourne

${ }^{2}$ Faculty of Medicine, University of Melbourne

\section{Keywords}

blood gas analysis, chronic obstructive pulmonary disease, oxygen inhalation therapy

Aust Prescr 2022:45:21-4 https://doi.org/10.18773/ austprescr.2022.007 


\section{Ambulatory oxygen therapy}

Ambulatory oxygen may be provided for patients who have:

- severe resting hypoxaemia and are physically active - in order to maximise the survival benefit by increasing the duration of their therapy

- an improvement in exercise capacity in response to ambulatory oxygen in a laboratory-based functional exercise test (usually a 6-minute walk test).

Despite some small acute benefits during laboratorybased tests, an Australian double-blind randomised controlled trial of oxygen therapy or air in patients with COPD without significant resting hypoxaemia found no greater relief of dyspnoea during activities of daily living in the oxygen group. ${ }^{4}$ This raises the possibility that the small benefits in both groups were related to a placebo effect or an effect of gas flow on the face. ${ }^{5}$

\section{Oxygen therapy during pulmonary rehabilitation}

Oxygen supplementation during pulmonary rehabilitation in patients with COPD who desaturate with exertion is no more beneficial than supplemental air. This was shown in a double-blind randomised controlled trial, comparing oxygen and air delivered at $6 \mathrm{~L} /$ minute. ${ }^{6}$ These results accord with those of a previous meta-analysis.?

\section{Nocturnal oxygen therapy}

Two small studies, reported over 20 years ago, investigated the impact of nocturnal oxygen therapy in patients with COPD who desaturated below $85 \%$ or $90 \%$ for more than a third of the night. Although one study showed a trend to improved pulmonary artery pressures in those randomised to receive nocturnal oxygen, no benefit was observed in the other study.8,9 The International Nocturnal Oxygen (INOX) trial also investigated patients with COPD and nocturnal desaturation. It was designed to test whether supplemental oxygen delivered via a concentrator would delay death or progression to long-term continuous oxygen therapy for longer than sham oxygen (air delivered via the identical device). ${ }^{10}$ Recruitment and retention difficulties led to premature stopping of the trial, after recruitment of only 243 out of a projected 600 patients, with no benefits observed. Overall, the evidence to date does not support the use of nocturnal oxygen in patients without severe daytime hypoxaemia.

\section{Oxygen for moderate hypoxaemia}

The Long-Term Oxygen Treatment Trial originally aimed to test whether supplemental oxygen would improve survival in patients with COPD and moderate resting hypoxaemia (pulse oximetry:
$\mathrm{SpO}_{2}$ 89-93\%). Recruitment difficulties led to extension of the entry criteria to include exerciseinduced desaturation and modification of the outcome measure to also include first hospitalisation for any cause. Compared to patients who did not use oxygen, there were no differences in any of the primary or secondary outcomes of the trial. The conclusion was that long-term supplemental oxygen in patients with stable COPD and resting or exercise-induced moderate desaturation has no benefit." These results were consistent with a small study with similar entry criteria which found that oxygen had no mortality benefit in patients with moderate hypoxaemia. ${ }^{12}$

\section{Palliative oxygen therapy}

Home oxygen is often sought for managing intractable dyspnoea, but, in the absence of significant hypoxaemia, there is no convincing evidence that it provides greater benefit than sham oxygen. ${ }^{13}$ Even in the presence of hypoxaemia and where underlying therapies have been maximised, oxygen may not relieve dyspnoea. Other palliative therapies including fans and opioids may be more appropriate for symptom management.

\section{Assessment of oxygen requirements}

Physicians often first become aware of a patient's hypoxaemia when the patient is admitted to hospital for an exacerbation of COPD. Oxygen is then often prescribed at hospital discharge, but this practice is not evidence-based. A New Zealand study reported that over a third of patients found to fulfil the criteria for long-term continuous oxygen therapy at hospital discharge no longer did so two months later. ${ }^{14}$ Guidelines therefore recommend reviewing patients 4-8 weeks after discharge to assess their requirements for oxygen. ${ }^{15}$

To determine eligibility for long-term continuous oxygen therapy, the Thoracic Society of Australia and New Zealand (TSANZ) Adult Domiciliary Oxygen Therapy Clinical Practice Guideline recommends arterial blood gas analysis while the patient is breathing room air. This is because of the known inherent variability of measuring oxygen saturation with pulse oximetry. ${ }^{15}$

Assessments should be made at least one month after the patient has quit smoking. There should also be regular reviews to confirm any ongoing need and the adequacy of oxygen therapy, or the need for patients using oxygen for exertion to progress to long-term continuous oxygen therapy. ${ }^{15}$

For patients who do not fulfil the criteria for long-term continuous oxygen therapy, but who desaturate on exertion, a blinded trial of portable oxygen versus air may be appropriate to determine whether there is any improvement in dyspnoea or distance walked. Then, 
after discussion with the patient, a trial at home may be in order, with a review to assess any benefit and the need for ongoing therapy.

\section{Contraindications, adverse effects and dangers}

Oxygen therapy is an absolute contraindication in patients who smoke because it is a fire risk. Open flames in the house such as from gas stoves or open fires may also present a risk. Identified issues surrounding the burden of therapy include decreased mobility, discomfort relating to the nasal prongs and noise relating to the device, to name a few. ${ }^{16}$

It is important that patients are aware that oxygen is a drug and should not be adjusted without consultation with the prescribing physician or therapist.

There is accumulating evidence regarding the burden placed on patients and carers by oxygen therapy, particularly ambulatory oxygen. Education about the potential benefits (or lack thereof) and burdens should occur when patients undergo assessment for home oxygen therapy. Patients benefit from discussing their beliefs and concerns, as their beliefs about oxygen influence its use. ${ }^{17}$

\section{Oxygen supplies}

In Australia there are three main methods of oxygen delivery. These are stationary concentrators for continuous use, and portable cylinders or portable concentrators for use during exertion.

While the TSANZ Guideline provides evidence-based guidance, the Australian states and territories vary in their interpretations and application of this advice and in their provision of oxygen therapy. ${ }^{18}$ There are different programs across the country to access home oxygen, for example the State-Wide Equipment Program in Victoria and the Medical Aids Subsidy Scheme in Queensland.

Further information on programs for oxygen supply in various states in Australia is available from:

- State-wide Equipment Program (Vic.)

- Medical Aids Subsidy Scheme (Qld)

- Enable NSW (NSW)

- Respiratory Health Network (WA)

- SA Health Home Oxygen Therapy (SA)

Useful information for patients is available through the Lung Foundation Australia.

\section{Conclusion}

Oxygen therapy improves mortality in patients with COPD and severe hypoxaemia. The results of trials in COPD during the 1980s have been extrapolated to patients with other lung conditions. Any benefits of oxygen in patients with milder degrees of hypoxaemia who may desaturate on exertion or nocturnally are unclear and require further study. Adequate discussion of patients' beliefs and concerns about oxygen therapy is important and impacts their use of home therapy. $\varangle$

Conflicts of interest: none declared

\section{REFERENCES}

1. Pilcher J, Beasley R. Acute use of oxygen therapy. Aust Prescr 2015;38:98-100. https://doi.org/10.18773/austprescr.2015.033

2. Stuart-Harris C, Bishop JM, Clark TJH, Dornhorst AC, Cotes JE, Flenley DC, et al. Long term domiciliary oxygen therapy in chronic hypoxic cor pulmonale complicating chronic bronchitis and emphysema: report of the Medical Research Council Working Party. Lancet 1981;1:681-6. https://doi.org/10.1016/S0140-6736(81)91970-X

3. Nocturnal Oxygen Therapy Trial Group. Continuous or nocturnal oxygen therapy in hypoxemic chronic obstructive lung disease: a clinical trial. Ann Intern Med 1980;93:391-8. https://doi.org/10.7326/0003-4819-93-3-391

4. Moore RP, Berlowitz DJ, Denehy L, Pretto JJ, Brazzale DJ, Sharpe K, et al. A randomised trial of domiciliary, ambulatory oxygen in patients with COPD and dyspnoea but without resting hypoxaemia. Thorax 2011;66:32-7. https://doi.org/ 10.1136/thx.2009.132522

5. Swan F, Newey A, Bland M, Allgar V, Booth S, Bausewein C et al. Airflow relieves chronic breathlessness in people with advanced disease: an exploratory systematic review and meta-analyses. Palliat Med 2019;33:618-33. https://doi.org/ $10.1177 / 0269216319835393$

6. Alison JA, McKeough ZJ, Leung RW, Holland AE, Hill K Morris NR, et al. Oxygen compared to air during exercise training in COPD with exercise-induced desaturation. Eur Respir J 2019;53:1802429. https://doi.org/10.1183/13993003.02429-2018

7. Nonoyama ML, Brooks D, Lacasse Y, Guyatt GH, Goldstein RS. Oxygen therapy during exercise training in chronic obstructive pulmonary disease. Cochrane Database Syst Rev 2007:CD005372. https://doi.org/10.1002/14651858.CD005372.pub2
8. Fletcher EC, Luckett RA, Goodnight-White S, Miller CC, Qian W, Costarangos-Galarza C. A double-blind trial of nocturnal supplemental oxygen for sleep desaturation in patients with chronic obstructive pulmonary disease and a daytime $\mathrm{PaO} 2$ above $60 \mathrm{~mm} \mathrm{Hg}$. Am Rev Respir Dis 1992;145:1070-6. https://doi.org/10.1164/ajrccm/145.5.1070

9. Chaouat A, Weitzenblum E, Kessler R, Charpentier C, Enrhart M, Schott R, et al. A randomized trial of nocturnal oxygen therapy in chronic obstructive pulmonary disease patients. Eur Respir J 1999;14:1002-8. https://doi.org/10.1183/ 09031936.99.14510029

10. Lacasse $Y$, Sériès F, Corbeil F, Baltzan M, Paradis B, Simão P, et al.; INOX Trial Group. Randomized trial of nocturnal oxygen in chronic obstructive pulmonary disease. N Engl J Med 2020;383:1129-38. https://doi.org/10.1056/NEJMoa2013219

11. Albert RK, Au DH, Blackford AL, Casaburi R, Cooper JA, Criner GJ, et al.; Long-Term Oxygen Treatment Trial Research Group. A randomized trial of long-term oxygen treatment for COPD with moderate desaturation. N Engl J Med 2016;375:1617-27. https://doi.org/10.1056/NEJMoa1604344

12. Górecka D, Gorzelak K, Sliwiński P, Tobiasz M, Zieliński J. Effect of long-term oxygen therapy on survival in patients with chronic obstructive pulmonary disease with moderate hypoxaemia. Thorax 1997;52:674-9. https://doi.org/10.1136/ thx.52.8.674

13. Abernethy AP, McDonald CF, Frith PA, Clark K, Herndon JE 2nd, Marcello J, et al. Effect of palliative oxygen versus room air in relief of breathlessness in patients with refractory dyspnoea: a double-blind, randomised controlled trial. Lancet 2010;376:784-93. https://doi.org/10.1016/S0140-6736(10)61115-4 
14. Eaton TE, Grey C, Garrett JE. An evaluation of short-term oxygen therapy: the prescription of oxygen to patients with chronic lung disease hypoxic at discharge from hospital. Respir Med 2001;95:582-7. https://doi.org/10.1053/ rmed.2001.1106

15. McDonald CF, Whyte K, Jenkins S, Serginson J, Frith P. Clinical practice quideline on adult domiciliary oxygen therapy: executive summary from the Thoracic Society of Australia and New Zealand. Respirology 2016;21:76-8. https://doi.org/10.1111/resp.12678

16. Jaturapatporn D, Moran E, Obwanga C, Husain A. Patients' experience of oxygen therapy and dyspnea: a qualitative study in home palliative care. Support Care Cancer 2010;18:765-70. https://doi.org/10.1007/s00520-010-0860-7
17. Kelly CA, Maden M. How do respiratory patients perceive oxygen therapy? A critical interpretive synthesis of the literature. Chron Resp Dis 2014;11:209-28. https://doi.org/ 10.1177/147997231455156

18. Serginson JG, Yang IA, Armstrong JG, Cooper DM, Matthiesson AM, Morrison SC, et al. Variability in the rate of prescription and cost of domiciliary oxygen therapy in Australia. Med J Aust 2009;191:549-53. https://doi.org/ 10.5694/j.1326-5377.2009.tb03308.x 